\title{
Using community health workers can lead to positive sexual behavior outcomes among people living with HIV
}

Population Council

Follow this and additional works at: https://knowledgecommons.popcouncil.org/departments_sbsr-rh

Part of the International Public Health Commons, Public Health Education and Promotion Commons, and the Social and Behavioral Sciences Commons

How does access to this work benefit you? Let us know!

\section{Recommended Citation}

"Using community health workers can lead to positive sexual behavior outcomes among people living with HIV," APHIA II Operations Research Project in Kenya OR Summary. Nairobi: Population Council, 2011. 


\title{
Using community health workers can lead to positive sexual behavior outcomes among people living with HIV
}

\begin{abstract}
Using community-based health workers to provide information and counsel people living with HIV as well as make referrals for antiretroviral therapy can lead to increased uptake of ART among those eligible but not on treatment, and to positive sexual behavior outcomes. HIV prevention and care programs should therefore work with CHWs to increase the reach and impact of their activities.
\end{abstract}

\section{Background}

While the coverage of antiretroviral therapy has expanded globally in recent years, a large number of people living with HIV (PLHIV) are not on treatment for a variety of reasons, or because they do not yet require it. However, it has been found that considerable proportions of PLHIV engage in unprotected sexual behaviors and increases in the incidence of sexually transmitted infections have been documented among PLHIVs, indicating that they are much in need of prevention services. Unfortunately, prevention interventions targeting this group in the community are not common; in addition, because they were not in regular contact with the health services as those on ART, they are less likely to receive any prevention information at all.

\section{A pilot intervention}

In 2010 and early 2011, APHIA II OR Project conducted an operations research project in Mombasa District to test a community-based risk-reduction strategy for PLHIV who were not on ART. In the intervention implemented in Changamwe Division, community health workers recruited and followed a cohort of PLHIV who were aged 18 and over, sexually active but not on ART over six months, and conducted one-to-one counseling using materials adapted from CDC/NASCOP resources on prevention with positives. Where possible, at least one of the visits included the PLWH's intimate partner, who was encouraged to get tested if they had not been already. Upon enrolment into the study, each of the 606 participants was interviewed for baseline data collection; the interview was repeated at the end of the six-month followup period.

\begin{tabular}{|l|l|}
\hline Site & Intervention elements \\
\hline $\begin{array}{l}\text { Intervention } \\
\text { (Changamwe) }\end{array}$ & $\begin{array}{l}\text { V CHW-initiated intervention } \\
\text { (Condom provision, referral of } \\
\text { partners for HIV testing, risk- } \\
\text { reduction counseling, referrals } \\
\text { to ART and care, promoting } \\
\text { disclosure) }\end{array}$ \\
& V Routine healthcare services at HC \\
\hline $\begin{array}{l}\text { Comparison } \\
\text { (Likoni) }\end{array}$ & V Routine healthcare services at HC \\
& x No CHW-initiated intervention \\
\hline
\end{tabular}

\section{Evaluation Findings}

- The intervention led to significant reduction in multiple sexual partners among target group: Only $19 \%$ of respondents in the intervention arm reported that they had more than two sexual partners over the previous three months, a drop from $41 \%$ 
at baseline. In the comparison arm, the reduction was much less, from $25 \%$ at baseline to $23 \%$ at endline.

- Improved rates of disclosure of HIV status to intimate partners was recorded: The proportion of study participants exposed to the intervention who had disclosed their HIV status to their intimate partner(s) rose from 52\% at the baseline to $83 \%$ at endline; in the comparison arm, the proportion increased marginally from $70 \%$ to $76 \%$.

- Improved condom use in intervention arm: Condom use at last sex improved significantly among the intervention group from $43 \%$ at baseline to $90 \%$ at endline among the males, and from 31\% to $90 \%$ among the females; in the comparison group, there was a slight increase (37\% to $46 \%$ ) among men, and none among women.

- Improved use of contraception: An increase was noted in the proportion of participants using contraception among the group exposed to the intervention, from $59 \%$ at baseline to $78 \%$ at endline. There was a much less increase in the comparison arm, from $54 \%$ to $56 \%$. Use of condoms and another method (dual protection) also increased among the intervention group, from $25 \%$ to $82 \%$, compared to $39 \%$ to $33 \%$ in the comparison group.

\section{Recommendations}

- This research demonstrated that CHWs can successfully provide information and counseling on prevention and treatment to PLHIV, who are outside the ambit of health services.

- CHWs can address important gaps in HIV-related knowledge and create awareness about HIV re-infection, status disclosure and ART treatment, and successfully link PLHIV with health services.

- It is recommended that HIV programs use community health workers to implement prevention interventions targeting healthy HIV positive individuals in the community, and to provide ongoing support to newly diagnosed clients, who may not yet be eligible for ART.

Source:

APHIA II OR Project. 2011. "Prevention with Positives: A community-based intervention study".

Nairobi, Kenya: Population Council.

For more information, contact:

Harriet Birungi, Project Director, APHIA II OR Project in Kenya/Population Council,

hbirungi@popcouncil.org,

www.popcouncil.org

(C) 2011 The Population Council, Inc. 